\title{
PERBANDINGAN HASIL BELAJAR ANTARA PEMBELAJARAN DENGAN MENGGUNAKAN MEDIA MANIPULATIF DENGAN PEMBELAJARAN KONVENSIONAL
}

\author{
${ }^{1}$ Lidya Dita Rizki, ${ }^{2}$ Nurul Astuty Yensy B, ${ }^{3}$ Rusdi \\ 1,2,3 Program Studi Pendidikan Matematika JPMIPA FKIP Universitas Bengkulu \\ Email: ${ }^{1}$ lidyadita1@gmail.com, ${ }^{2}$ nurulastutyyensy@yahoo.com, ${ }^{3}$ rusdipendmat12@gmail.com
}

\begin{abstract}
Abstrak
Penelitian ini bertujuan untuk mengetahui perbandingan hasil belajar antara pembelajaran menggunakan media manipulatif dengan pembelajaran konvensional. Populasi penelitian ini adalah siswa kelas V MIN 1 Kota Bengkulu. Sampel penelitian ini adalah siswa Kelas VC untuk kelas kontrol tidak menggunakan media manipulatif dan kelas VA untuk kelas eksperimen menerapkan penggunaan media manipulatif. Teknik pengumpulan data dengan menggunakan instrumen tes diberikan posttest (setelah pembelajaran berlangsung). Untuk analisis data menggunakan uji-t dengan data berdistribusi normal dan homogen.Berdasarkan hasil penelitian diperoleh nilai rata-rata siswa yang diajar dengan menggunakan media manipulatif lebih tinggi dibandingkan dengan nilai rata-rata siswa yang diajar tanpa menggunakan media manipulatif. Dari hasil penelitian diketahui hasil uji-t dengan $t$ hitung $(14,57)$

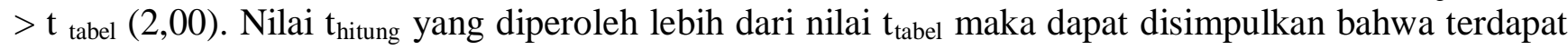
pengaruh penggunaan media manipulatif terhadap hasil belajar siswa kelas V MIN 1 Kota Bengkulu.

kata kunci: hasil belajar, media manipulatif.
\end{abstract}

\begin{abstract}
This study aims to determine the comparison of learning outcomes between learning using manipulative media with conventional learning. Population of this research is student class V MIN 1 Kota Bengkulu. Data collection techniques using test given posttest (after learning persisting). Sample of this research is student class VC for the control class apply not to use media manipulative and class VA for experiment class to apply use media manipulative. Data collection techniques using test given posttest (after learning persisting). For data analysis using t-test with normal distribution of data and homogeneous. Based on the results obtained by the average value of students being taught by using manipulative media is higher than the average student is taught without using manipulative media. From result of research known result of $t$-test with $t_{\text {hitung }}(14,57)>t_{\text {tabel }}(2,00)$. $t$ hitung value obtained more than tabel value it can be concluded that there is influence of the use of manipulative media to the students learning outcomes class V MIN 1 Kota Bengkulu.
\end{abstract}

keywords: achievement, media manipulatives.

\section{PENDAHULUAN}

Matematika merupakan pengetahuan yang ada di dalam kehidupan sehari-hari. Matematika dapat memberikan pengalaman belajar yang sangat bermanfaat untuk kelangsungan hidup di masa depan. Sebagaimana pendapat Muhsetyo (2007: 1.26) pembelajaran matematika adalah proses pemberian pengalaman belajar kepada peserta didik melalui serangkaian kegiatan yang terencana sehingga peserta didik memperoleh kompetensi tentang bahan matematika yang dipelajari.
Hudojo (2005:35) Matematika adalah suatu alat untuk mengembangkan cara berpikir. Karena itu matematika sangat diperlukan baik untuk kehidupan sehari-hari maupun dalam mengadapi kemajuan IPTEK sehingga matematika perlu dibekalkan kepada setiap peserta didik sejak SD, bahkan sejak taman kanak-kanak hingga perguruan tinggi.

Dalam membimbing siswa untuk belajar seorang guru harus bisa memberi variasi pembelajaran yang menarik karena dimana tidak asing lagi matematika dianggap pelajaran yang menakutkan dan membosakan. Segala sesuatu yang dapat dipergunakan untuk 
merangsang pikiran, perasaan, perhatian dan kemampuan atau ketrampilan pembelajar sehingga dapat mendorong terjadinya proses belajar.

Djamarah (1996), metode pembelajaran konvensional adalah metode pembelajaran tradisional atau disebut juga dengan metode ceramah, karena sejak dulu metode ini telah dipergunakan sebagai alat komunikasi lisan antara guru dengan anak didik dalam proses belajar dan pembelajaran. Dalam pembelajaran sejarah metode konvensional ditandai dengan ceramah yang diiringi dengan penjelasan, serta pembagian tugas dan latihan. Siswa adalah penerima informasi secara pasif, dimana siswa menerima pengetahuan dari guru dan pengetahuan diasumsinya sebagai badan dari informasi dan keterampilan yang dimiliki sesuai dengan standar

Amir (2014: 80) Media pembelajaran adalah suatu perantara yang digunakan oleh pendidik/guru untuk menyalurkan pesan atau informasi kepada siswanya sehingga siswa tersebut dapat terangsang ketika mengikuti kegiatan pembelajaran. Dapat dikatakan pula media pembelajaran dapat memudahkan siswa untuk menerima pembelajaran yang disampaikan pendidik/guru. Dengan media siswa akan lebih mudah memahami konsep yang dipelajari.

Perkembangan ilmu pengetahuan dan teknologi semakin mendorong upaya-upaya pembaharuan dalam pemanfaatan hasil-hasil teknologi dalam proses belajar mengajar. Menurut Muhsetyo (2007: 2.31) mendefinisikan bahwa "Media manipulatif adalah media yang dapat dimanipulasikan dengan tangan, diputar, dipegang, dibalik, dipindah, diatur atau ditata atau dipotongpotong". Dari pendapat tersebut dapat dipahami bahwa bahan manipulalatif yaitu bahan yang dapat dimain-mainkan dengan tangan. Alat ini terkait langsung dan bagian dari penjelasan konsep uraian-uraian materi yang disampaikan.

Media manipulatif merupakan bendabenda, alat-alat, inovatif atau bantuan yang dapat digunakan untuk membantu dalam memahami suatu konsep atau topik matematika. Pentingnya penggunaan media manipulatif dalam pembelajaran matematika untuk suatu benda yang dimanipulasi oleh untuk dalam penyampaian pelajaran matematika agar siswa dapat lebih mudah memahamai konsep dengan standar-standar yang diajukan agar pembelajaran lebih efektif dan mampu meningkatkan hasil belajar siswa lebih baik.

Melalui media pembelajaran manipulatif diharapkan siswa berperan aktif dalam proses pembelajaran berlangsung dan siswa dapat belajar sambil bermain membuat variasi saat pembelajaran menyenangkan sehingga tidak membuat siswa bosan dan jenuh. Peneliti tertarik untuk menggungkapkan dan meneliti bagaimanakah jika dalam pembelajaran matematika memanfaatkan media pembelajaran berupa benda-benda manipulatif sebagai bantuan untuk membantu penanaman konsep matematika.

Berdasarkan latar belakang yang dikemukakan, maka rumusan masalah dalam penelitian ini adalah "Apakah hasil belajar dengan menggunakan media manipulatif lebih lebih baik dengan pembelajaran tanpa menggunakan media manipulatif ?

Adapun tujuannya adalah untuk apakah hasil belajar dengan menggunakan media manipulatif lebih lebih baik dengan pembelajaran tanpa menggunakan media manipulatif.

\section{METODE}

Jenis penelitian yang digunakan dalam penelitian ini adalah penelitian eksperimen semu. Populasi dalam penelitian ini adalah semua siswa kelas V di MIN 1 Kota Bengkulu tahun ajaran 2016/2017. Sampel penelitian ini kelas VA sebagai kelas eksperimen dan kelas VC sebagai kelas kontrol.

Intrumen yang digunakan berbentuk soal objektif pilihan ganda 15 soal yang akan diuji coba terlebih dahulu dengan kelas yang sudah mempelajari materi yang sudah ditentukan. Selanjutnya instrumen tersebut diuji. Untuk menguji validitas item tes digunakan rumus koefisien korelasi product moment dengan rumus : 


$$
r_{p b i}=\frac{M_{p}-M_{t}}{S_{t}} \sqrt{\frac{p}{q}}
$$

(Arikunto 2009:79)

Dengan kriteria:

Jika $r_{p b i} \geq \mathrm{r}_{\text {tabel }}$ maka butir soal valid.

Jika $r_{p b i} \leq \mathrm{r}_{\text {tabel }}$ maka butir soal tidak valid.

\section{Reliabilitas}

Menurut Sudjana (2009:16) Reliabilitas alat penilaian adalah ketetapan atau alat tersebut dalam menilai apa yang dinilainya.

Uji Reliabilitas

Reliabilitas tes hasil belajar dapat dihitung menggunakan rumus :

$$
r=\left(\frac{n}{n-1}\right)\left(\frac{S_{t}{ }^{2}-\sum p q}{S_{t}{ }^{2}}\right)
$$

(Lestari, K.E \& Yudhanegara, 2015:215)

\section{Keterangan:}

Dalam pemberian interpretasi terhadap koefisien reliabilitas tes $\left(\mathrm{r}_{11}\right)$ digunakan patokan sebagai berikut:

1) Apabila $r_{11} \geq 0,70$ berarti tes yang sedang diuji reliabilitasnya dinyatakan telah memiliki reliabilitas yang tinggi (reliabel).

2) Apabila $r_{11} \leq 0,70$ berarti tes yang sedang diuji reliabilitasnya dinyatakan belum memiliki reliabilitas yang tinggi, sehingga soal tes tidak digunakan.

(Winarni, 2011:193)

Taraf kesukaran

Tingkat kesukaran (TK) pada masingmasing butir soal dihitung dengan menggunakan rumus:

$$
T K=\frac{S_{A}+S_{B}}{n \text { maks }}
$$

Jihad dan Haris (2013:182)

Interpretasi tingkat kesukaran digunakan pada pendapat Sudjana (Jihad dan Haris, 2013: 182)

\section{Tabel 3 Kriteria Tingkat Kesukaran}

\begin{tabular}{|c|c|}
\hline Interval & Tingkat Kesukaran \\
\hline $0 \leq \mathrm{TK} \leq 0,30$ & Sukar \\
$0,30<\mathrm{TK} \leq 0,70$ & Sedang \\
$0,70<\mathrm{TK} \leq 1,00$ & Mudah \\
\hline
\end{tabular}

Kriteria soal yang digunakan adalah soal dengan klasifikasi soal sukar dan sedang (Arikunto, 2009: 210).

Daya pembeda

Daya pembeda (DP) pada masing-masing butir soal tes ditentukan dengan rumus:

$$
D P=\frac{S_{A}+S_{B}}{\frac{1}{2} n \cdot \text { maks }}
$$

Jihad dan Haris (2013: 181)

Interpretasi nilai DP mengacu pada pendapat Ruseffendi (Jihad dan Haris, 2013: 181), yaitu:

Tabel 3 Kriteria Daya Pembeda

\begin{tabular}{|c|c|}
\hline Daya Pembeda & Evaluasi \\
\hline $\mathrm{DP} \leq 0.19$ & Tidak Baik \\
\hline $0,19<\mathrm{DP} \leq 0,29$ & Cukup Baik \\
\hline $0,29<\mathrm{DP} \leq 0,39$ & Baik \\
\hline $\mathrm{DP} \geq 0.40$ & Sangat Baik \\
\hline
\end{tabular}

Kriteria daya pembeda yang digunakan dalam penelitian ini adalah soal dengan kriteria daya pembeda sangat baik, baik, dan cukup baik.

\section{Pengujian Persyaratan Analisis Uji Normalitas}

Rumus yang digunakan untuk menguji hipotesis adalah rumus chi kuadrat yaitu :

$$
\chi^{2}=\sum \frac{\left(f_{o}-f_{h}\right)^{2}}{f_{h}}
$$

(Sugiyono, 2012: 107)

Hipotesis diterima atau ditolak dengan membandingkan $x^{2}$ hitung dengan nilai kritis $x^{2}{ }_{\text {tabel }}$ pada taraf signifikan 5\%. Bila harga chikuadrat hitung lebih kecil atau sama dengan harga chi-kuadrat tabel $\left(x^{2}{ }_{\text {hitung }} \leq x^{2}{ }_{\text {tabel }}\right)$, maka distribusi data dinyatakan normal.

(Arikunto, 2010:312-314)

\section{Uji Homogenitas}

Menurut Sugiyono (2014: 276) rumus yang digunakan dalam mencari perbandinagn varian adalah sebagai berikut:

$$
F_{\text {hitung }}=\frac{\text { Varian terbesar }}{\text { Varian terkecil }}
$$

Sampel dapat dikatakan homogeny apabila $F$ hitung lebih kecil daripada $<F_{\text {tabel }}$ dengan taraf signifikan $5 \%$.

\section{Pengujian Hipotesis}


Sugiyono Mengatakan (2014: 197) apabila sampel berkorelasi misalnya dengan membandingkan sebelum dan sesudah treatment atau perlakuan dan menggunakan $t$ test sampel dengan rumus sebagai berikut:

$$
t=\frac{\bar{X}_{1}-\bar{X}_{2}}{\sqrt{\frac{\left(n_{1}-1\right) S_{1}^{2}+\left(n_{2}-1\right) S_{2}^{2}}{n_{1}+n_{2}-2}\left(\frac{1}{n_{1}}+\frac{1}{n_{2}}\right)}}
$$

Jika nilai $t_{\text {hitung }}>t_{\text {tabel }}$ pada taraf signifikan $5 \%$ dan derajat kebebasan $(\mathrm{dk})=n_{1}+n_{2}-2$, maka terdapat pengaruh yang disignifikan. Menurut Sugiyono (2014: 153) jika asumsi ttest tidak terpenuhi (misalnya data harus normal) maka untuk menguji hipotesis digunakan statistikk nonparametris dua sampel independent yaitu dengan menggunakan persamaan Mann-Withney U-test.

\section{HASIL DAN PEMBAHASAN}

Penelitian dilakukan di MIN 1 Kota Bengkulu pada Jum'at, 31 Maret 2017 sampai dengan Selasa, 25 April 2017. Penelitian ini dilakukan sebanyak 12 pertemuan dimana 6 pertemuan dikelas eksperimen dan 6 dikelas kontrol. Sebelum melakukan penelitian peneliti melakukan observasi dan wawancara kepada salah satu guru MIN 1 Kota Bengkullu ibu Ririn Khairunnisa, M.Pd merupakan wali kelas V.

Dari hasil observasi dan wawancara diperoleh kedua sampel yaitu kelas VA dan VC hal ini dikarena nilai rata-rata ulangan harian yang sama. Berdasarkan nilai rata-rata tersebut ditentukan bahwa kelas VA sebagai kelas eksperimen yaitu yang diberikan perlakuan dengan pembelajaran menggunakan media manipulatif, sedangkan kelas VC sebagai kelas kontrol dengan pembelajaran konvesional tanpa menggunakan media manipulatif.

Sebelum tes diberikan kepada kedua sampel, terlebih dahulu soal tes diuji validitas oleh validator. Validator yang menilai tes yang akan diuji coba ada 2 orang ialah guru matematika MIN 1 Kota Bengkulu dan dosen pedidikan matematika. Berdasarkan pertimbangan ahli, semua butiran soal telah valid tetapi ada beberapa soal yang harus disajikan dengan jelas dan bahasa yang digunakan harus lebih jelas. Setelah dilakukan uji validasi dengan validator ternyta soal dapat diuji cobakan terhadap sampel lain yang sudah mempelajari materi sifat-sifat bangun datar dan dilakukan uji coba instrumen belajar yang berbentuk soal objektif berupa pilihan ganda dengan jumlah 15 soal.

\begin{tabular}{|c|c|c|c|c|}
\hline \multicolumn{5}{|c|}{ Rekapitulasi Hasil Uji Coba Soal } \\
\hline $\begin{array}{l}\text { Butir } \\
\text { soal }\end{array}$ & Validitas & Reliabilitas & $\begin{array}{l}\text { Tingkat } \\
\text { Kesukaran }\end{array}$ & $\begin{array}{c}\text { Daya } \\
\text { Pembeda }\end{array}$ \\
\hline 1 & $\begin{array}{l}\text { TIDAK } \\
\text { VALID } \\
\end{array}$ & Reliabel & Mudah & $\begin{array}{c}\text { Sangat } \\
\text { Baik }\end{array}$ \\
\hline 2 & $\begin{array}{l}\text { TIDAK } \\
\text { VALID }\end{array}$ & Reliabel & Mudah & $\begin{array}{c}\text { Sangat } \\
\text { Baik }\end{array}$ \\
\hline 3 & $\begin{array}{l}\text { TIDAK } \\
\text { VALID }\end{array}$ & Reliabel & Sedang & $\begin{array}{c}\text { Tidak } \\
\text { Baik }\end{array}$ \\
\hline 4 & VALID & Reliabel & Mudah & $\begin{array}{l}\text { Tidak } \\
\text { Baik }\end{array}$ \\
\hline 5 & VALID & Reliabel & Sedang & $\begin{array}{c}\text { Sangat } \\
\text { Baik }\end{array}$ \\
\hline 6 & VALID & Reliabel & Mudah & $\begin{array}{c}\text { Sangat } \\
\text { Baik }\end{array}$ \\
\hline 7 & VALID & Reliabel & Sedang & $\begin{array}{c}\text { Sangat } \\
\text { Baik }\end{array}$ \\
\hline 8 & $\begin{array}{l}\text { TIDAK } \\
\text { VALID }\end{array}$ & Reliabel & Sukar & $\begin{array}{l}\text { Tidak } \\
\text { Baik }\end{array}$ \\
\hline 9 & VALID & Reliabel & Mudah & $\begin{array}{l}\text { Sangat } \\
\text { Baik }\end{array}$ \\
\hline 10 & $\begin{array}{l}\text { TIDAK } \\
\text { VALID }\end{array}$ & Reliabel & Sedang & $\begin{array}{c}\text { Tidak } \\
\text { baik }\end{array}$ \\
\hline 11 & $\begin{array}{l}\text { TIDAK } \\
\text { VALID } \\
\end{array}$ & Reliabel & Sedang & Baik \\
\hline 12 & VALID & Reliabel & Sedang & $\begin{array}{c}\text { Sangat } \\
\text { Baik }\end{array}$ \\
\hline 13 & $\begin{array}{l}\text { TIDAK } \\
\text { VALID }\end{array}$ & Reliabel & Mudah & $\begin{array}{l}\text { Tidak } \\
\text { Baik }\end{array}$ \\
\hline 14 & VALID & Reliabel & Sedang & Baik \\
\hline 15 & VALID & Reliabel & Sedang & $\begin{array}{c}\text { Sangat } \\
\text { Baik }\end{array}$ \\
\hline
\end{tabular}

Rekapitulasi hasil uji coba soal diatas ada 7 soal yang tidak valid tetapi dapat digunakan dan ada beberapa soal yang bisa digunakan dengan revisi soal no 1, 8, 11 dan 13. Jadi, soal yang dapat digunakan untuk tes akhir belajar item soal no 1 (dengan revisi), no 4 , no 5 , no 6 , no 7 , no 8 (dengan revisi), no 9, no 11 (dengan revisi), no 12 , no 13 (dengan revisi), no 14 dan no 15.

\section{Analisis Deskriptif Hasil Belajar Siswa Kelas eksperimen}

Setelah selesai pembelajaran selama 5 kali pertemuan dikelas eksperimen, diberikan 
tes akhir (posttest). Soal posttest yang diberikan berupa soal objektif pilihan ganda, yang diikuti oleh 31 siswa. Pemberian posttest ini bertujuan untuk mengetahui nilai hasil belajar siswa, ratarata hasil belajar 79,68 dari jumlah siswa 31 orang dan skewness 0,42 ini berarti nilai skewness (mendekati nol) berdistribusi normal.

Untuk lebih jelasnya lihat pada kurva sebagai berikut :

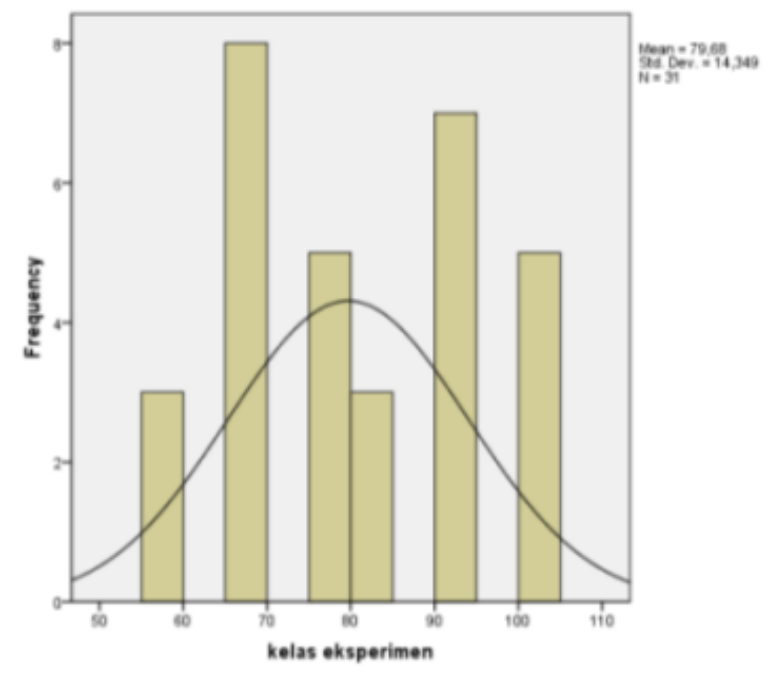

\section{Gambar 4 Kurva Histrogram Distribusi Kenormalan Kelas Eksperimen}

\section{Analisis Deskriptif Hasil Belajar Siswa Kelas Kontrol}

Setelah selesai pembelajaran selama 5 kali pertemuan dikelas kontrol, diberikan tes akhir (posttest). Soal posttest yang diberikan berupa soal objektif pilihan ganda, yang diikuti oleh 27 siswa. Pemberian posttest ini bertujuan untuk mengetahui nilai hasil belajar siswa, rata-rata hasil belajar 65,26 dari jumlah siswa 27 orang dan skewness 0,44 ini berarti nilai skewness (mendekati nol) berdistribusi normal. Untuk lebih jelasnya lihat pada kurva sebagai berikut :

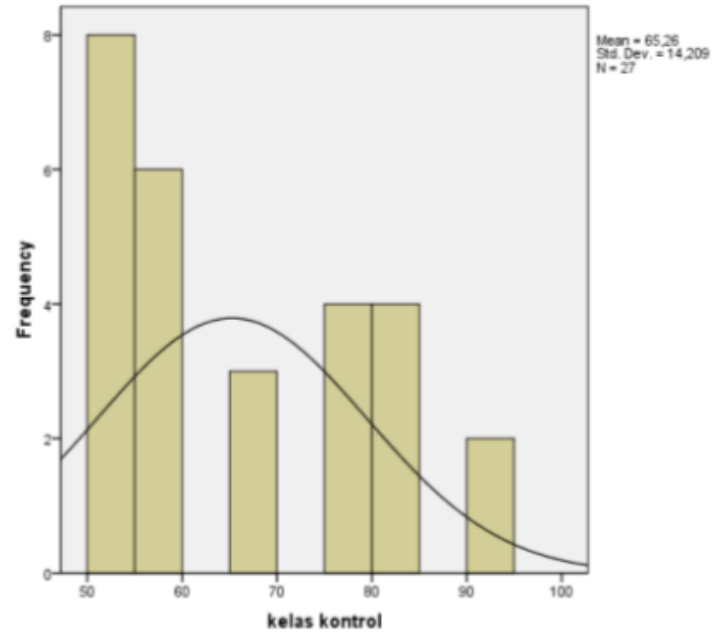

Gambar 4 Kurva Histrogram Distribusi Kenormalan Kelas Kontrol

Rekapitulasi hasil uji normalitas kelas eksperimen dan kelas kontrol dengan pengujian chi-kuadrat. Sampel berdistribusi normal karena $x^{2}{ }_{\text {hitung }}<x^{2}{ }_{\text {tabel }}$. Dimana nilai $x^{2}$ hitung pada kelas eksperimen yaitu 7,04 dan $x^{2}$ hitung pada kelas kelas kontrol yaitu 6,84 dengan $x^{2}{ }_{\text {tabel }}$ sebesar 11,07 pada taraf signifikan 5\% maka kedua data berdistribusi normal berarti $\mathrm{H}_{0}$ diterima.

Rekapitulasi hasil uji homogenitas pengujian uji $f$. Sampel bervarian homogen karena $F_{\text {hitung }}<F_{\text {tabel }}$. Dimana nilai $F_{\text {hitung }}$ sebesar 1,01 dan $F_{\text {tabel }}$ sebesar 1,90 pada taraf signifikan 5\% maka kedua data bervarian homogen.

Pengujian hipotesis dengan uji $t$, hasil pengujian kelas eksperimen dan kelas kontrol dengan nilai $t_{\text {hitung }}$ yaitu 14,57 dengan nilai $t_{\text {tabel }}$ yaitu 2,00 dinyatakan bahwa $t_{\text {hitung }}$ $>t_{\text {tabel }}$ dengan $\mathrm{H}_{1}$ diterima. Dapat disimpulkan bahwa adannya perbandingan antara pembelajaran menggunakan media manipulatif dan pembelajaran tanpa menggunakan media manipulatif.

Tabel 4. Perbandingan hasil belajar

\begin{tabular}{|l|ll|}
\hline Kelas eksperimen & Kelas kontrol \\
\hline Siswa aktif terlibat & Siswa pasif & Siswa lebih banyak \\
diam & \\
\hline $\begin{array}{l}\text { Siswa langung } \\
\text { langibut }\end{array}$ & $\begin{array}{l}\text { Siswa lebih ribut } \\
\text { mengobrol }\end{array}$ \\
\hline $\begin{array}{l}\text { Siswa beraktivitas } \\
\text { dengan media }\end{array}$ & Siswa hanya \\
\hline Siswa mencari
\end{tabular}




\begin{tabular}{|l|l|}
\hline informasi & menerima infomasi \\
\hline
\end{tabular}

Berdasarkan hasil penelitian pembelajaran pada kelas eksperimen dengan menggunakan media manipulatif menggunakan kertas origami. Penggunaan media pembelajaran merupakan salah satu usaha untuk mencapai tujuan pembelajaran. Dengan menggunakan media pembelajaran dapat memancing semangat, motivasi dan minat daya tarik anak untuk semangat belajar.

Kelas eksperimen kelas yang diberi perlakuan dangan pembelajaran menggunakan media siswa terlibat langsung dalam penggunaan media. Dimana dalam pembelajaran ini siswa dapat menemukan sifatsifat bangun datar dengan sendiri dan juga dapat membuktikan sifat-sifat tersebut dengan media yang ada.

Selama proses pembelajaran pada kedua kelas sampel dilaksanakan berdasarkan Rencana Pelaksanaan Pembelajaran (RPP) yang telah direncanakan sebelumnya. Pembelajaran pada kelas eksperimen (VA) dengan menggunakan media manipulatif anak terlibat langsung dapat dilihat pada (Lampiran 23, gambar 1-4). Sedangkan kelas kontrol dilakukan pembelajaran konvensional dengan panduan buku paket dan menerima materi dari penjelasan guru.

Pada pembelajaran langsung siswa memang lebih baik terlibat langsung dalam proses pembelajaran dengan media manipulatif. Siswa diminta membuat gambar bangun datar dikertas origami dan siswa diberi kesempatan membuat media bangun datar dengan ukuran yang berbeda dan bervariasi dengan teman yang lainnya. Setelah itu guru dan siswa menemukan sifat-sifat bangun datar dan membuktikan dengan media salah satunya membuktikan apakah suatu sisi bangun datar tersebut sama panjang atau tidak dengan cara melipat bangun datar tersebut atau dengan mengukur dengan pengaris. Siswa menggunakan media manipulatif kertas origami yang sudah dibentuk bangun datar persegi panjang misalnya pada bangun datar persegi panjang siswa mampu menemukan dan membuktikan sifat-sifat bangun datar tersebut dengan media manipulatif kertas origami berbentuk bangun datar persegi panjang .
Anak dapat melihat dua sisi yang berhadapan sama panjang lalu anak membuktikan dengan melipat dua pada bagian lebar sisi-sisi dan terbukti sama panjang, lalu membuktikan satu sisi lagi pada sisi panjang dengan melipat bangian sisi-sisi panjang dan anak yang membuktikan dengan menggunakan pengaris, begitu juga pada besar sudut, panjang diaognal. Membuktikan dengan cara dilipat, menggunakan pengaris dan menggunakan busur untuk sudut dan seterusnya pada bangun datar lainnya. Sependapat dengan Muhsetyo (2007: 2.31) menyatakan bahwa "media manipulatif adalah media yang dibuat dapat diputar, dipegang, dibolak-balik, dipindah, diatur, ditata atau di potong-potong”.

Pertemuan selanjutnya pada kelas eksperimen. Siswa mandiri tanpa arahkan dalam penggunaan media mereka bisa dengan cara mereka membentuk media dan membuat media menjadi sebuah media dengan bangun datar yang telah ditentukan. Siswa juga dapat menyebutkan sifat-sifat bangun datar tersebut dan mampu membuktikan sifat-sifat bangun datar tersebut dengan media dan bisa memberi penjelasan kepada teman sekelasnya. Sangat terlihat semangat dan rasa ingin tahu siswa dalam pembelajaran berlangsung dimana siswa lebih aktif.

\section{PENUTUP \\ SIMPULAN}

Berdasarkan penelitian yang telah dilakukan pada siswa kelas V MIN 1 Kota Bengkulu pada materi sifat-sifat bangun datar dan perhitungan data dapat disimpulkan adanya perbandingan pembelajaran menggunakan media manipulatif dan pembelajaran tanpa menggunakan media manipulatif dengan nilai rata-rata hasil perhitungan pengujian hipotesis dengan menggunakan uji-t menyatakan nilai $t_{\text {hitung }}(14,57)>t_{\text {tabel }}(2,00)$.

\section{SARAN}

Berdasarkan hasil penelitian. Saran yang dapat diberikan oleh peneliti ialah :

1. Untuk guru agar dapat menggunakan media manipulatif dalam pembelajaran matematika agar siswa tidak bosan saat pembelajaran berlangsung. 


\section{DAFTAR PUSTAKA}

Amir, Almira M.Si. 2014. Pembelajaran

Matematika SD dengan Menggunakan

Media Manipulatif. Jurnal pendidikan.

Forum Pendagogik Vol. IV. No 01.

2014.

Arikunto, Suharsimi, Prof. Dr. 2009. Dasar-

Dasar Evaluasi Pendidikan Jakarta:

Bumi Aksara. 2010. Prosedur

Penelitian Suatu Pendekatan Praktik.

Jakarta: Rineka Cipta

Jihad, Asep dan Abdul Hamid. 2013. Evaluasi

Pembelajaran. Yogyakarta: Multi

Pressindo

Hudojo, Herman. 2005. Pengembangan

Kurikulum dan Pembelajaran Matematika.

Malang: Universitas Negeri Malang.

Lestari, K.E \& Yudhanegara, M.R.2015. Penelitian Pendidikan Matematika. Bandung:Refika Aditama.

Muhsetyo, Gatot dkk. 2007. Pembelajaran Matematika SD. Jakarta: Universitas Terbuka.

Sudjana, Nana. 2005. Penilaian Hasil Proses Belajar Mengajar. Bandung: PT Remaja Rosdakarya

Sugiyono, 2012. Statistika untuk Penelitian.

Bandung: Alfabeta . 2014. Metode Penelitian Kuantitatid Kualitatif dan $R \& D$. Bandung: Alfabeta 